\title{
Characterization of the MLO gene family in Rosaceae and gene expression analysis in Malus domestica
}

\author{
Stefano Pessina ${ }^{1,2}$, Stefano Pavan ${ }^{3}$, Domenico Catalano ${ }^{4}$, Alessandra Gallotta ${ }^{3}$, Richard GF Visser ${ }^{2}$, Yuling Bai ${ }^{2}$, \\ Mickael Malnoy ${ }^{1 *}$ and Henk J Schouten ${ }^{2^{*}}$
}

\begin{abstract}
Background: Powdery mildew (PM) is a major fungal disease of thousands of plant species, including many cultivated Rosaceae. PM pathogenesis is associated with up-regulation of MLO genes during early stages of infection, causing down-regulation of plant defense pathways. Specific members of the MLO gene family act as PM-susceptibility genes, as their loss-of-function mutations grant durable and broad-spectrum resistance.

Results: We carried out a genome-wide characterization of the MLO gene family in apple, peach and strawberry, and we isolated apricot MLO homologs through a PCR-approach. Evolutionary relationships between MLO homologs were studied and syntenic blocks constructed. Homologs that are candidates for being PM susceptibility genes were inferred by phylogenetic relationships with functionally characterized $M L O$ genes and, in apple, by monitoring their expression following inoculation with the PM causal pathogen Podosphaera leucotricha.

Conclusions: Genomic tools available for Rosaceae were exploited in order to characterize the MLO gene family. Candidate MLO susceptibility genes were identified. In follow-up studies it can be investigated whether silencing or a loss-of-function mutations in one or more of these candidate genes leads to PM resistance.
\end{abstract}

Keywords: Rosaceae, MLO, Powdery mildew, Malus domestica

\section{Background}

Powdery mildew (PM) is a major fungal disease for thousands of plant species [1], including cultivated Rosaceae such as apple (Malus domestica), apricot (Prunus armeniaca), peach (Prunus persica), and strawberry (Fragaria $x$ ananassa). Powdery mildew occurs in all major growing regions of Rosaceous crops, leading to severe losses [2]. The major PM causal agents are Podosphaera leucotricha in apple [2], Sphaerotheca pannosa var. persicae in peach [3], Podosphaera tridactyla in apricot [4] and Podosphaera aphanis (syn. Sphaerotheca macularis f. sp. fragariae) in strawberry [5]. Powdery mildew shows similar symptoms in the four species: white spots appear on young green tissues, particularly leaves in the first days after opening,

\footnotetext{
* Correspondence: mickael.malnoy@fmach.it; henk.schouten@wur.nl 'Department of Genomics and Biology of Fruit Crops, Fondazione Edmund Mach, via E. Mach 1, 38010 San Michele all'Adige, Italy

${ }^{2}$ Wageningen UR Plant Breeding, Wageningen University and Research Centre, P.O Box 16, 6700 AA Wageningen, The Netherlands

Full list of author information is available at the end of the article
}

whereas mature leaves show some resistance. Infected leaves crinkle, curl, and prematurely drop. Blossoms and fruits are not the primary targets of PM fungi, but infections of these tissues are possible [2,3,5]. In peach, apricot and apple, PM spores overwinter in buds and then in spring, with the reprise of vegetative growth, the spores start a new infection $[2,3]$.

Cultivars resistant to PM are fundamental in order to reduce the use of pesticides in agricultural practices. The usual strategy in breeding focuses on dominant plant resistance genes (R-genes), however these genes often originate from wild-relatives of the cultivated species, and thus interspecific crossability barriers could prevent their introgression [6]. Moreover, in case of a successful cross, several undesirable traits are incorporated with the R-gene, making extensive backcrossing necessary, which is time-consuming in woody species. Finally, the durability of R-genes is generally limited due to the appearance of virulent strains of the pathogen, which can 
overcome resistance in a few years [7]. Two examples are Venturia inaequalis race 6 , which is able to overcome Rvi6 resistance to scab in apple [8], and $P$. leucotricha strains able to breakdown $\mathrm{Pl}-1$ and $\mathrm{Pl}-2$, two major PM R-genes of apple [9].

An alternative to the use of R-genes is based on plant susceptibility genes (S-genes), defined as genes whose loss-of-function results in recessively inherited resistance [10]. Barley mlo PM resistance, first characterized in 1942, is a remarkable example of immunity due to the absence of an S-gene, as it derives from a loss-of-function mutation in the MLO (Mildew Locus $\boldsymbol{O}$ ) gene, encoding for a protein with seven transmembrane domains [11,12]. mlo resistance has long been considered as a unique form of immunity, characterized by durability, broad-spectrum effectiveness and recessive inheritance [13]. However, the characterization of the sources of resistance in other plant species, such as Arabidopsis [14], pea [15,16] and tomato [17], has revealed that resistance resulting from loss-of-function mutations in $M L O$ functional orthologs is more common than previously thought. Therefore, it has been suggested that the inactivation of $M L O$ susceptibility genes could represent a valid strategy to introduce PM resistance across a broad range of cultivated species [10].

Histological characterization of mlo resistance revealed that it is based on a pre-penetration defense system, associated with the formation of cell-wall appositions $[14,18]$ and at least partially dependent on the actin cytoskeleton [19]. It has been suggested that functional MLO proteins negatively regulate vesicle-associated and actin-dependent defense pathways at the site of attempted PM penetration [20]. MLO proteins are therefore targeted by PM fungi as a strategy to induce pathogenesis. The early stages of PM infection are associated with an increase in transcript abundance of $M L O$ susceptibility genes, showing a peak at six hours after inoculation. This has been shown to occur in tomato [17], barley [21], pepper [22] and grape [23,24].

$M L O$ susceptibility genes are members of a gene family which shows tissue specific expression patterns and are involved in a variety of physiological processes, besides the response to PM fungi: one of the $15 M L O$ genes of Arabidopsis, AtMLO7, is involved in pollen tube reception by the embryo sac and its mutation results in reduced fertility [25]. Two other Arabidopsis genes, named AtMLO4 and AtMLO11, are involved in the control of root architecture, as mutants with null alleles of these two genes display asymmetrical root growth and exaggerated curvature [26].

Previous phylogenetic analysis of the MLO protein family identified six clades [23]. Currently, all MLO proteins functionally related to PM susceptibility in dicot species appear in a single clade, namely Clade V [14,17,23,24]. Similarly, Clade IV harbours all characterized PM susceptibility proteins from monocots [20,27].
$M L O$ genes have been intensively studied in many monocots and dicots, but very little has been performed in Rosaceae. In this investigation, we characterized the $M L O$ gene family in a number of Rosaceous species, with respect to their structural, genomic and evolutionary features. Moreover, we monitored the transcript abundances of apple $M L O$ homologs following $P$. leucotricha inoculation in three apple cultivars.

\section{Results \\ In silico and in vitro characterization of Rosaceae MLO homologs}

A database search for Rosaceae $M L O$ homologs produced 21 significant matches in peach, 23 in strawberry and 28 in apple. Of these, six (five from $M$. domestica and one from $F$. vesca) showed a very limited alignment region with other $M L O$ genes, whereas eight (two from $M$. domestica, two from $P$. persica and four from $F$. vesca) were characterized by markedly different length with respect to $M L O$ homologs reported in the genomes of Arabidopsis and grapevine $[23,28]$, i.e. less than 350 amino acids (aa) or more than 700 aa. Details on genomic localization amino acid number, putative transmembrane domains and predicted exon/intron structure of the remaining homologs, together with information about the $M L O$ homologs nomenclature chosen in this study is provided in Tables 1, 2 and 3.

Peach and apricot are evolutionary very close to each other, and show a high degree of homology in DNA sequence. Phylogenetic analysis (see next paragraph) indicated peach homologs PpMLO1, PpMLO3 and PpMLO4 as candidates for being required for PM susceptibility. Therefore, we used the sequences of these genes to design primers to identify full-length apricot $M L O$ genes. This approach resulted in the amplification and the successive characterization of three $M L O$ sequences, which were by analogy named PaMLO1, PaMLO3, and PaMLO4 (deposited in the NCBI database with the accession numbers KF177395, KF177396, and KF177397, respectively).

\section{Phylogenetic relations and inference of orthology}

We performed a phylogenetic study on the newly identified Rosaceae MLO proteins. The dataset was completed with four homologs recently characterized in Rosa hybrida (rose) [30] (RhMLO1, RhMLO2, RhMLO3 and RhMLO4), the complete Arabidopsis thaliana AtMLO protein family [14], a series of MLO homologs which have been functionally associated with PM susceptibility, namely tomato (Solanum lycopersicum) SIMLO1 [17], pea (Pisum sativum) PsMLO1 [15,16], pepper (Capsicum annuum) CaMLO2 [27], lotus (Lotus japonicus) LjMLO1 [15], barrel clover (Medicago truncatula) MtMLO1 [15], barley (Hordeum vulgare) HvMLO [11], rice (Oryza sativa) OsMLO2 [31], wheat (Triticum aestivum) TaMLO_B1 and TaMLO_A1b [31], and grapevine (Vitis vinifera) VvMLO14, 
Table 1 Members of the MdMLO gene family as predicted in M. domestica cv. Golden Delicious genome sequence

\begin{tabular}{|c|c|c|c|c|c|c|c|c|}
\hline Gene & Accession number $^{a}$ & Chr. & Starting position (Mb) & Clade & Introns & $\mathrm{TM}^{\mathrm{b}}$ & Amino acids & Conserved $\mathrm{aa}^{\mathrm{c}}$ \\
\hline MdMLO1 & MDP0000177099 & 2 & 1.02 & $\|$ & 11 & 3 & 487 & 25 \\
\hline MdMLO2 & MDP0000240125 & 2 & 11.10 & I & 11 & 3 & 571 & 20 \\
\hline MdMLO3 & MDP0000168575 & 2 & 11.11 & I & 13 & 7 & 670 & 22 \\
\hline MdMLO4 & MDP0000207002 & 2 & 8.79 & III & 16 & 7 & 634 & 28 \\
\hline MdMLO5 & MDP0000163089 & 9 & 15.26 & v & 14 & 6 & 579 & 30 \\
\hline MdMLO6 & MDP0000119433 & 3 & 33.95 & $\|$ & 0 & 7 & 504 & 30 \\
\hline MdMLO7 & MDP0000123907 & n.d. & n.d. & V & n.d. & 6 & 561 & 28 \\
\hline MdMLO8 & MDP0000218520 & 2 & 11.11 & I & 9 & 4 & 390 & 14 \\
\hline MdMLO9 & MDP0000320797 & 2 & 27.20 & $\|$ & 10 & 5 & 454 & 28 \\
\hline MdMLO10 & MDP0000196373 & 3 & 26.97 & I & 13 & 6 & 539 & 28 \\
\hline MdMLO11 & MDP0000239643 & 4 & 9.84 & v & 12 & 8 & 575 & 28 \\
\hline MdMLO12 & MDP0000133162 & 6 & 0.81 & III & 13 & 5 & 516 & 28 \\
\hline MdMLO13 & MDP0000142608 & 7 & 7.48 & $\|$ & 12 & 6 & 351 & 18 \\
\hline MdMLO14 & MDP0000191469 & 8 & 29.25 & $\|$ & 10 & 5 & 395 & 23 \\
\hline MdMLO15 & MDP0000141595 & 9 & 7.54 & III & 15 & 6 & 647 & 24 \\
\hline MdMLO16 & MDP0000191848 & 9 & 21.12 & $\mathrm{VI}$ & 14 & 6 & 606 & 29 \\
\hline MdMLO17 & MDP0000145097 & 11 & 27.97 & I & 13 & 7 & 523 & 28 \\
\hline MdMLO18 & MDP0000928368 & 10 & 27.97 & VII & 12 & 7 & 502 & 30 \\
\hline MdMLO19 & MDP0000168714 & 12 & 16.23 & V & 13 & 7 & 590 & 30 \\
\hline MdMLO20 & MDP0000134649 & 13 & 11.61 & VIII & 13 & 5 & 589 & 27 \\
\hline MdMLO21 & MDP0000133760 & 15 & 24.99 & $\mathrm{VI}$ & 15 & 6 & 560 & 28 \\
\hline
\end{tabular}

${ }^{a}$ Available at http://www.rosaceae.org/gb/gbrowse/malus x domestica/.

${ }^{\mathrm{b}}$ Number of transmembrane domains in the predicted protein, as determined by InterPro prediction software (http://www.ebi.ac.uk/interpro/).

cnumber of conserved amino acids out of the 30 identified by Elliot et al. [29].

the only dicot MLO homolog known to belong to clade IV [23]. Clustering analysis using the UPGMA algorithm resulted in a total of eight distinct clades and no divergent lineage (Figure 1). Clade numbers from I to VI were assigned based on the position of Arabidopsis AtMLO homologs and barley HvMLO, according to the previous study of Feechan et al. [23]. The two additional clades (named VII and VIII) were found to include Rosaceae MLO homologs only, both having one homolog from $P$. persica, one from $F$. vesca and one from $M$. domestica. Further clustering analysis with a Neighbour-Joining algorithm resulted in merging clade VII and VIII (not shown).

Four apple MLO homologs (MdMLO5, MdMLO7, MdMLO11 and MdMLO19) and three MLO homologs from peach (PpMLO1, PpMLO3 and PpMLO4), apricot (PaMLO1, PaMLO3 and PaMLO4) and woodland strawberrry (FvMLO1, FvMLO4 and FvMLO12) were found to cluster together in the phylogenetic clade V, containing all the dicot MLO proteins experimentally shown to be required for PM susceptibility (e.g. [16,23]. One homolog from strawberry (FvMLO17) and one from peach (PpMLO12) were found to group, together with grapevine VvMLO14, in clade IV, which contains all monocot MLO proteins acting as PM susceptibility factors (Figure 1).

We used the GBrowse-Syn tool to detect syntenic blocks encompassing $P$. persica, $F$. vesca and $M$. domestica $M L O$ genes. As syntenic blocks derive from the evolution of the same chromosomal region after speciation, orthology between $M L O$ genes could be inferred. In total, twelve orthologous relationships were predicted between $P$. persica and $F$. vesca, nine between $P$. persica and $M$. domestica and eight between $F$. vesca and $M$. domestica (Table 4, Figure 2 and Additional file 1).

\section{Transcription of putative apple $M L O$ genes in response to Podosphaera leucotricha inoculation}

To identify $M L O$ genes that respond to the PM fungus $P$. leucotricha, we measured the transcript abundance of 19 out of 21 apple $M L O$ genes in leaves 4, 6, 8 and 24 hours after artificial inoculation with the pathogen, and compared these data with the ones of non-inoculated leaves. Three cultivars, Golden Delicious, Braeburn and Gala, were analysed in order to investigate whether up-regulation was comparable among them and results could therefore be generalized for all apple cultivars. Three genes, namely 
Table 2 Members of the PpMLO gene family as predicted in Prunus persica genome sequence

\begin{tabular}{|c|c|c|c|c|c|c|c|c|}
\hline Gene & Accession number ${ }^{a}$ & Chr. & Starting position $(\mathrm{Mb})$ & Clade & Introns & $\mathrm{TM}^{\mathrm{b}}$ & Amino acids & Conserved $a a^{c}$ \\
\hline PpMLO1 & ppa003207m & 6 & 6.82 & V & 14 & 7 & 593 & 30 \\
\hline PpMLO2 & ppa003435m & 7 & 18.38 & III & 14 & 8 & 574 & 30 \\
\hline PpMLO3 & ppa003437m & 6 & 21.99 & V & 13 & 7 & 574 & 30 \\
\hline PpMLO4 & ppa003466m & 2 & 21.03 & V & 14 & 7 & 572 & 30 \\
\hline PpMLO5 & ppa003706m & 4 & 10.92 & I & 14 & 8 & 555 & 30 \\
\hline PpMLO6 & ppa004012m & 7 & 22.64 & $\|$ & 14 & 6 & 535 & 29 \\
\hline PpMLO7 & ppa004508m & 8 & 21.17 & $\|$ & 0 & 7 & 506 & 29 \\
\hline PpMLO8 & ppa004621m & 6 & 22.01 & $\mathrm{Vl}$ & 14 & 6 & 499 & 29 \\
\hline PpMLO9 & ppa004687m & 4 & 2.59 & VII & 11 & 7 & 496 & 29 \\
\hline PpMLO10 & ppa004866m & 2 & 13.73 & $\|$ & 11 & 7 & 488 & 29 \\
\hline PpMLO11 & ppa020172m & 1 & 43.04 & I & 14 & 4 & 561 & 30 \\
\hline PpMLO12 & ppa020311m & 5 & 0.82 & IV & 13 & 7 & 566 & 30 \\
\hline PpMLO13 & ppa021048m & 4 & 15.57 & VIII & 12 & 5 & 510 & 24 \\
\hline PpMLO14 & ppa022847m & 6 & 6.80 & $\mathrm{Vl}$ & 14 & 6 & 550 & 29 \\
\hline PpMLO15 & ppa024476m & 7 & 17.63 & I & 14 & 8 & 539 & 26 \\
\hline PpMLO16 & ppa024488m & 5 & 0.76 & III & 14 & 6 & 504 & 30 \\
\hline PpMLO17 & ppa024581m & 6 & 8.95 & $\|$ & 13 & 6 & 463 & 27 \\
\hline PpMLO18 & ppa026565m & 6 & 22.00 & $\mathrm{Vl}$ & 13 & 6 & 416 & 25 \\
\hline PpMLO19 & ppb024523m & 1 & 42.04 & $\|$ & 13 & 5 & 446 & 23 \\
\hline
\end{tabular}

${ }^{a}$ Available at http://www.rosaceae.org/gb/gbrowse/prunus_persica/.

${ }^{b}$ Number of transmembrane domains in the predicted protein, as determined by InterPro prediction software (http://www.ebi.ac.uk/interpro/).

c number of conserved amino acids out of the 30 identified by Elliot et al. [29].

Table 3 Members of the FvMLO gene family as predicted in Fragaria vesca genome sequence

\begin{tabular}{|c|c|c|c|c|c|c|c|c|}
\hline Gene & Accession number ${ }^{a}$ & Chr. & Starting position (Mb) & Clade & Introns & $\mathrm{TM}^{\mathrm{b}}$ & Amino acids & Conserved $\mathrm{aa}^{\mathrm{c}}$ \\
\hline FVMLO1 & mrna02774.1-v1.0-hybrid & n.d. & n.d. & V & 14 & 7 & 632 & 28 \\
\hline FVMLO2 & mrna03210.1-v1.0-hybrid & 3 & 14.46 & $\|$ & 11 & 5 & 528 & 20 \\
\hline FVMLO3 & mrna09651.1-v1.0-hybrid & 6 & 35.88 & III & 14 & 6 & 542 & 28 \\
\hline FVMLO4 & mrna09653.1-v1.0-hybrid & 6 & 35.90 & V & 14 & 7 & 573 & 30 \\
\hline FVMLO5 & mrna10166.1-v1.0-hybrid & 1 & 1.34 & $\|$ & 14 & 3 & 688 & 26 \\
\hline FVMLO6 & mrna10346.1-v1.0-hybrid & 3 & 12.52 & $\|$ & 7 & 2 & 385 & 15 \\
\hline FVMLO7 & mrna10363.1-v1.0-hybrid & 3 & 12.49 & $\|$ & 9 & 2 & 442 & 21 \\
\hline FVMLO8 & mrna10558.1-v1.0-hybrid & 2 & 19.08 & $\|$ & n.d. & 6 & 514 & 28 \\
\hline FVMLO9 & mrna11028.1-v1.0-hybrid & n.d. & n.a. & I & 10 & 4 & 434 & 18 \\
\hline FVMLO10 & mrna13023.1-v1.0-hybrid & 1 & 7.96 & III & 13 & 6 & 557 & 27 \\
\hline FVMLO11 & mrna14592.1-v1.0-hybrid & 1 & 8.77 & I & 13 & 7 & 548 & 28 \\
\hline FVMLO12 & mrna23198.1-v1.0-hybrid & 7 & 15.89 & V & 14 & 7 & 507 & 29 \\
\hline FVMLO13 & mrna26428.1-v1.0-hybrid & 7 & 17,79 & VIII & 11 & 5 & 558 & 20 \\
\hline FVMLO14 & mrna28541.1-v1.0-hybrid & n.d. & n.a. & III & 11 & 4 & 481 & 26 \\
\hline FVMLO15 & mrna29770.1-v1.0-hybrid & 3 & 7.36 & VII & 13 & 7 & 538 & 28 \\
\hline FVMLO16 & mrna31264.1-v1.0-hybrid & 3 & 30.51 & । & 16 & 8 & 579 & 28 \\
\hline FVMLO17 & mrna31498.1-v1.0-hybrid & 5 & 20.23 & IV & 11 & 5 & 531 & 27 \\
\hline FVMLO18 & mrna29285.1-v1.0-hybrid & 5 & 19.12 & V & 6 & 4 & 357 & 18 \\
\hline
\end{tabular}

${ }^{a}$ Available at http://www.rosaceae.org/gb/gbrowse/fragaria_vesca_v1.0-lg/ (hybrid).

${ }^{b}$ Number of transmembrane domains in the predicted protein, as determined by InterPro prediction software (http://www.ebi.ac.uk/interpro/).

cnumber of conserved amino acids out of the 30 identified by Elliot et al. [29]. 


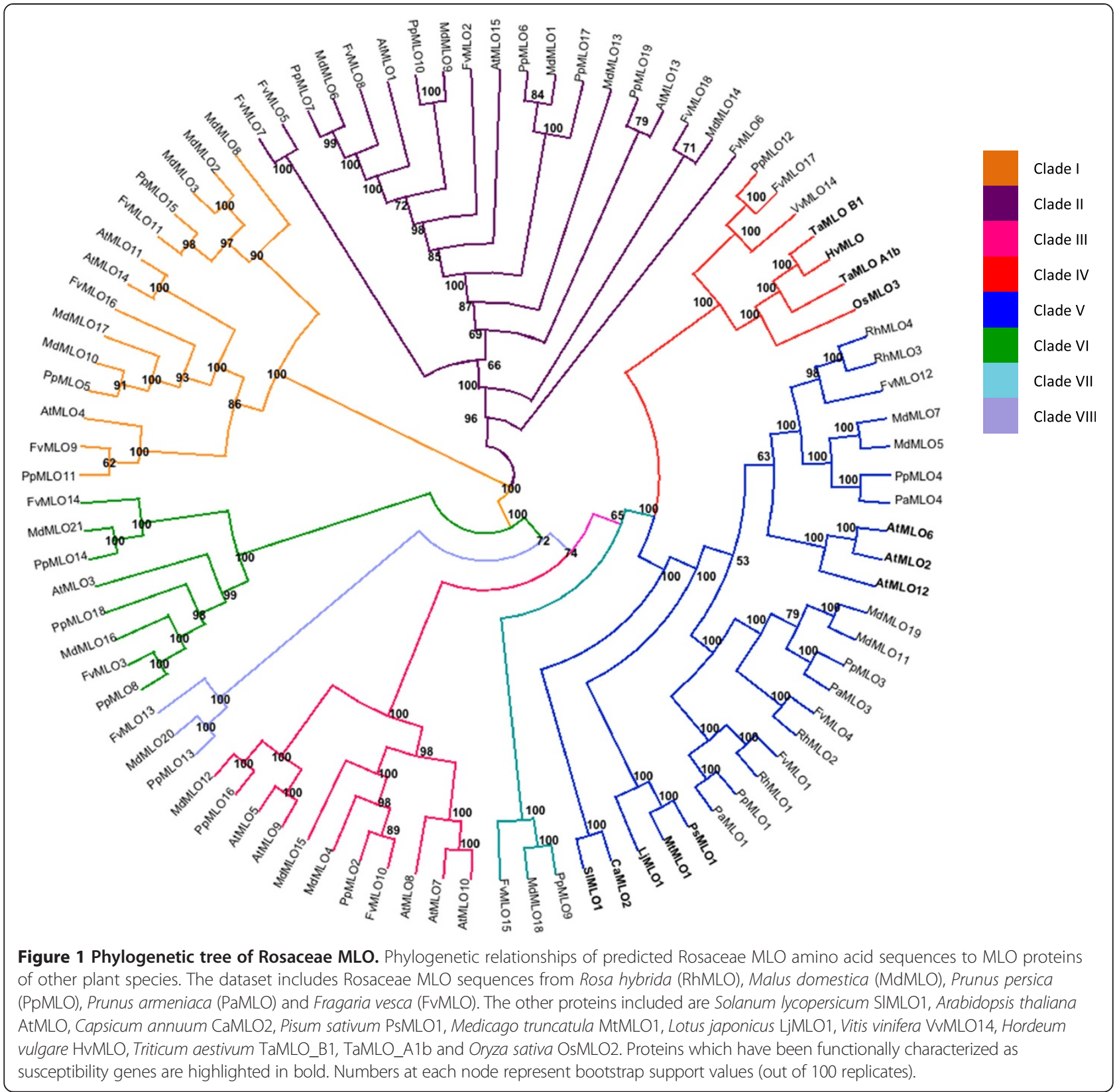

MdMLO11, MdMLO18 and MdMLO19, were found to be significantly up-regulated after inoculation with the pathogen (Figure 3 and Additional file 2). Up-regulation of these genes was about 2-fold compared to non-inoculated plants, with peaks of 4-fold up-regulation at very early time points ('Braeburn'- MdMLO11 - $6 \mathrm{hpi}$; 'Gala'- MdMLO18 4 hpi; 'Golden Delicious'- MdMLO19 - 6hpi). MdMLO11 and $M d M L O 18$ were up-regulated in all cultivars, while MdMLO19 was only up-regulated in 'Braeburn' and 'Golden Delicious'.

Two of the genes, MdMLO11 and MdMLO19 belong to Clade V, while $M d M L O 18$ belongs to the newly identified Clade VII (Figure 1).

\section{Discussion}

Genomic organization and phylogenetic relations between Rosaceae MLO homologs

We report here the identification, through an in silico approach, of $19 M L O$ homologs in the genome of peach and 18 in the genome of strawberry. This is consistent with the results of previous genome-wide studies carried out on dicotyledonous species, indicating the presence of $15 \mathrm{MLO}$ homologs in Arabidopsis, 17 in grapevine and 16 in tomato [9,13]; Appiano et al., unpublished results; [24]. Conversely, the number of $M L O$ homologs detected in apple (21) is lower than expected, considering that a relatively recent genomewide duplication event has occurred in the Pyreae tribe [32]. 
Table 4 Relations of orthology inferred between $P$. persica, $F$. vesca and $M$. domestica MLO homologs

\begin{tabular}{lcc}
\hline P. persica genes & F. vesca orthologs & M. domestica orthologs \\
\hline PpMLO2 & FVMLO10 & MdMLO15 \\
PpMLO3 & FVMLO4 & MdMLO19 \\
PpMLO4 & FVMLO12 & - \\
PpMLO5 & FVMLO16 & MdMLO10, MdMLO17 \\
PpMLO6 & FVMLO5 & MdMLO1 \\
PpMLO7 & FVMLO8 & - \\
PpMLO8 & FVMLO3 & - \\
PpMLO9 & FVMLO15 & MdMLO18 \\
PpMLO10 & FVMLO2 & MdMLO9 \\
PpMLO14 & FVMLO14 & MdMLO21 \\
PpMLO15 & FVMLO11 & - \\
PPMLO16 & - & MdMLO12 \\
PpMLO18 & FVMLO3 & - \\
\hline
\end{tabular}

Relations of orthology between PpMLO1, PpMLO3, PpMLO4 and apricot PaMLO1, PaMLO3, PaMLO4 were clearly suggested by the high percentage of sequence identity between these homolog genes, which was $97,3 \%, 98,8 \%$ and $96,7 \%$, respectively.

Most $P p M L O, F v M L O$ and $M d M L O$ homologs appeared to be widely distributed within the respective genomes (Tables 1, 2 and 3), indicating segmental duplication as the prevailing evolutionary mechanism for the Rosaceae $M L O$ gene family. However, we also found cases of clusters of adjacent homologs (PpMLO3, PpMLO8 and PpMLO18, PpMLO12 and PpMLO16, PpMLO1 and PpMLO14, FvMLO3 and FvMLO4, FvMLO6 and FvMLO7, MdMLO2, $M d M L O 3$ and $M d M L O 8$ ), which are likely the result of tandem duplication events.

Inference of phylogenetic relationships between MLO proteins revealed the presence of apple, strawberry, peach and apricot homologs in the clade $\mathrm{V}$, containing all dicot MLO homologs shown so far to be involved in PM susceptibility, thus making them candidates to act as susceptibility factors. Although the simple clustering in clade $\mathrm{V}$ is not enough to recognize a gene as a susceptibility factor, it does provide the first evidence for functionality and allows for the reduction in the number of candidates for further functional analysis. Clade IV, that contains functional MLO susceptibility homologs from monocots, was found to include one homolog from $F$. vesca (FvMLO17) and one from P. persica (PpMLO12). In accordance with this finding, a MLO homolog from the dicot species $V$. vinifera also clusters in clade IV [23,24]. Figure 1). Interestingly, phylogenetic analyses carried out in this study also revealed the presence of one or two additional clades, depending on the type of phylogenetic reconstruction (UPGMA or Neighbour-Joining), which were not reported to occur in earlier investigations. Moreover, they appear to be characteristic of Rosaceae, since they contain only homologs from this family. Clearly, the exclusivity for Rosaceae of these clade(s) needs to be confirmed by further studies containing a larger dataset of MLO proteins. Additional studies could be also addressed to the functional characterization of Rosaceae MLO homologs grouped in clade VII. Indeed, this appears to be basal to both clade IV and clade V (Figure 1), and thus might have contained ancestral proteins which later on evolved into PM susceptibility factors.

\section{Synteny between apple, peach and woodland strawberry MLO genes}

We took advantage of recent developments in Rosaceae genomics in order to detect synteny between $P$. persica, $F$. vesca and $M$. domestica chromosomal regions containing $M L O$ homologs. This permitted the inference of ortholgous relationships between $M L O$ genes in these species. Notably, all predicted $M L O$ orthologs from different Rosaceae species, fell in the same phylogenetic clade (Tables 1, 2 and 3; Figure 1 and Additional file 1). This is to be expected, since orthologs generally share the same function and thus are characterized by a high level of sequence conservation. It is noteworthy that the chromosomal localization of predicted $M L O$ orthologs between $P$. persica, $M$. domestica and $F$. vesca is in accordance with the results of the synteny study performed after the release of the three genomes [33,34]. In particular, genes situated on peach scaffold 2,7 and 8 were predicted to have orthologs on strawberry chromosome 7,1 and 2, respectively, whereas genes on peach scaffold 4 were predicted to have orthologs on strawberry chromosomes 2 or 3 (Table 4). FvMLO3 was predicted to be orthologous to two peach $M L O$ genes, PpMLO8 and $P p M L O 18$, which are localised in close proximity to each other on peach scaffold 6 and grouped together in clade VI. In this case, we hypothesize a relation of co-orthology due to the occurrence of a recent tandem duplication event in the peach genome. Similarly, PpMLO5 and $F v M L O 16$ were predicted to be orthologs of two apple $M L O$ genes, $M d M L O 10$ and $M d M L O 17$, located on chromosomes 3 and 11. This is consistent with indications of duplications of large segments of these two chromosomes during the evolution of the apple genome [32].

\section{Transcription of apple putative $M L O$ genes in response to $P$. leucotricha inoculation}

In barley, pea and tomato, only one of the clade $\mathrm{V} M L O$ homologs seems to be involved in powdery mildew susceptibility, whereas in A. thaliana three $M L O$ genes in Clade $\mathrm{V}$ are required to be inactivated in order to achieve a fully resistant phenotype [16,27]. This implies that, within Clade V $M L O$ genes, a further selection might be required to identify PM susceptibility genes. Accumulating 


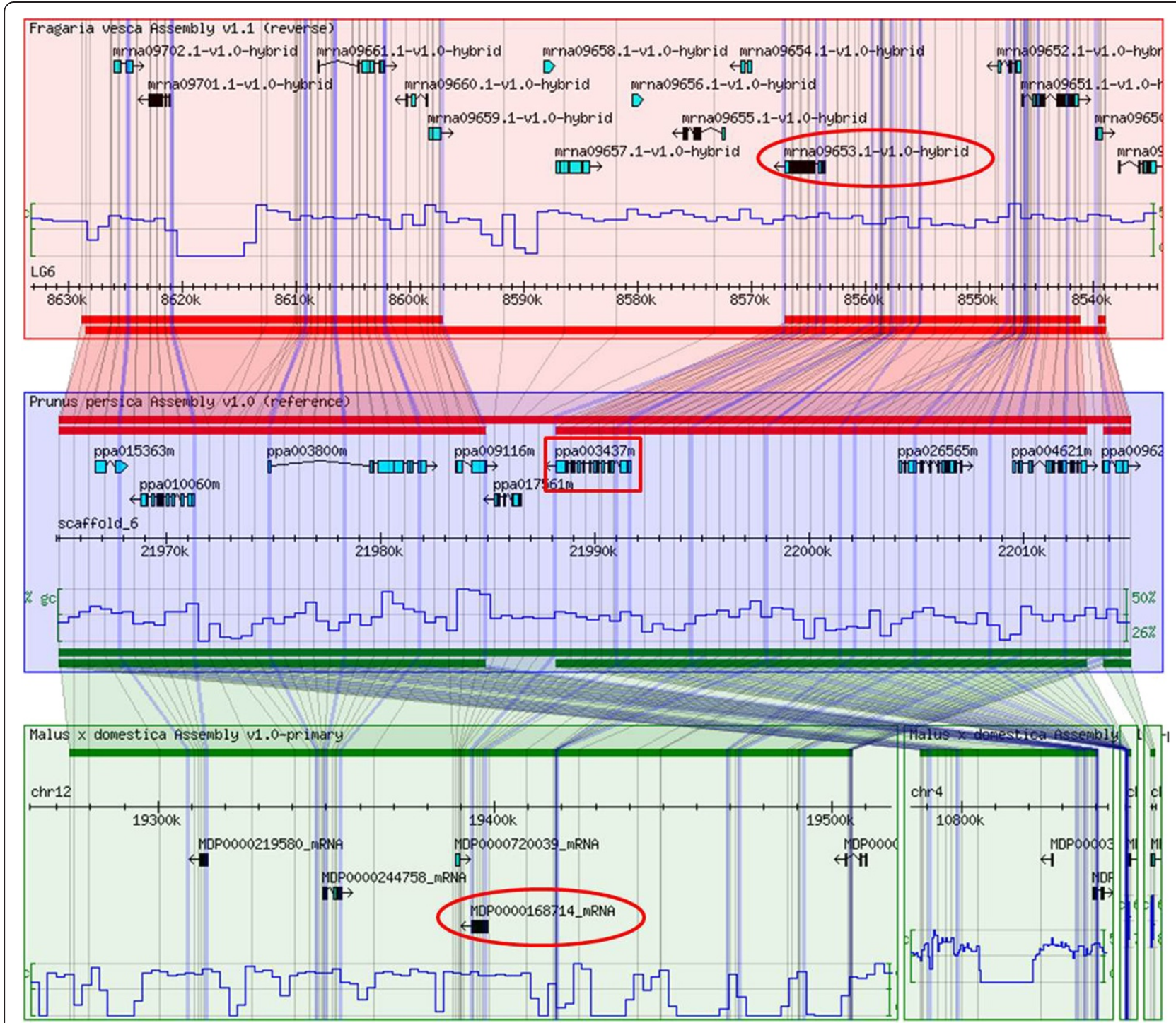

Figure 2 Synteny between apple, peach and strawberry. Results of search for $F$. vesca and $M$. domestica chromosomal regions syntenic to a P. persica $50 \mathrm{~kb}$ stretch including the MLO homolog PpMLO3 (corresponding to ppa003437m in the genomic database of Rosaceae), boxed. Shaded polygons indicate aligned regions between genomes. Grid lines are meant to indicate insertions/deletions between the genomes of F. vesca and M. domestica with respect to the P. persica reference sequence. Strawberry FVMLO4 and apple MdMLO19 (named in the figure as mrna09653.1-v1.0-hybrid and MDP0000168714, according to the nomenclature provided in this paper), predicted to be PpMLO3 orthologs, are indicated with circles.

evidence indicates that $M L O$ susceptibility genes are up-regulated upon challenge with powdery mildew fungi [17]. Therefore, we analysed the expression level of apple $M L O$ genes identified in this study in response to the interaction with $P$. leucotricha. Three pathogendependent gene up-regulations were detected. Two upregulated $M L O$ homologs, $M d M L O 11$ and $M d M L O 19$, encode for proteins falling in clade $\mathrm{V}$, thus making them likely candidates to act as PM susceptibility genes in apple. MdMLO11 and MdMLO19 are located on chromosomes 4 and 12 respectively, and are therefore both generated from a duplication event in the 9- chromosome ancestor of apple [32]. A third pathogendependent up-regulated gene, $M d M L O 18$, was found, which encodes a protein grouping in the newly identified Clade VII (Figure 1). The presence of a PM upregulated gene outside clade $\mathrm{V}$ is consistent with transcriptome analyses recently performed in tomato (Appiano et al., unpublished results). Apple clade $\mathrm{V}$ also contains two genes, MdMLO5 and MdMLO7, which show no significant changes in expression following inoculation. Accordingly, the lack of up-regulation of some clade $\mathrm{V}$ $M L O$ genes has been observed in grapevine and tomato [23,24]; Appiano et al., unpublished results). The 


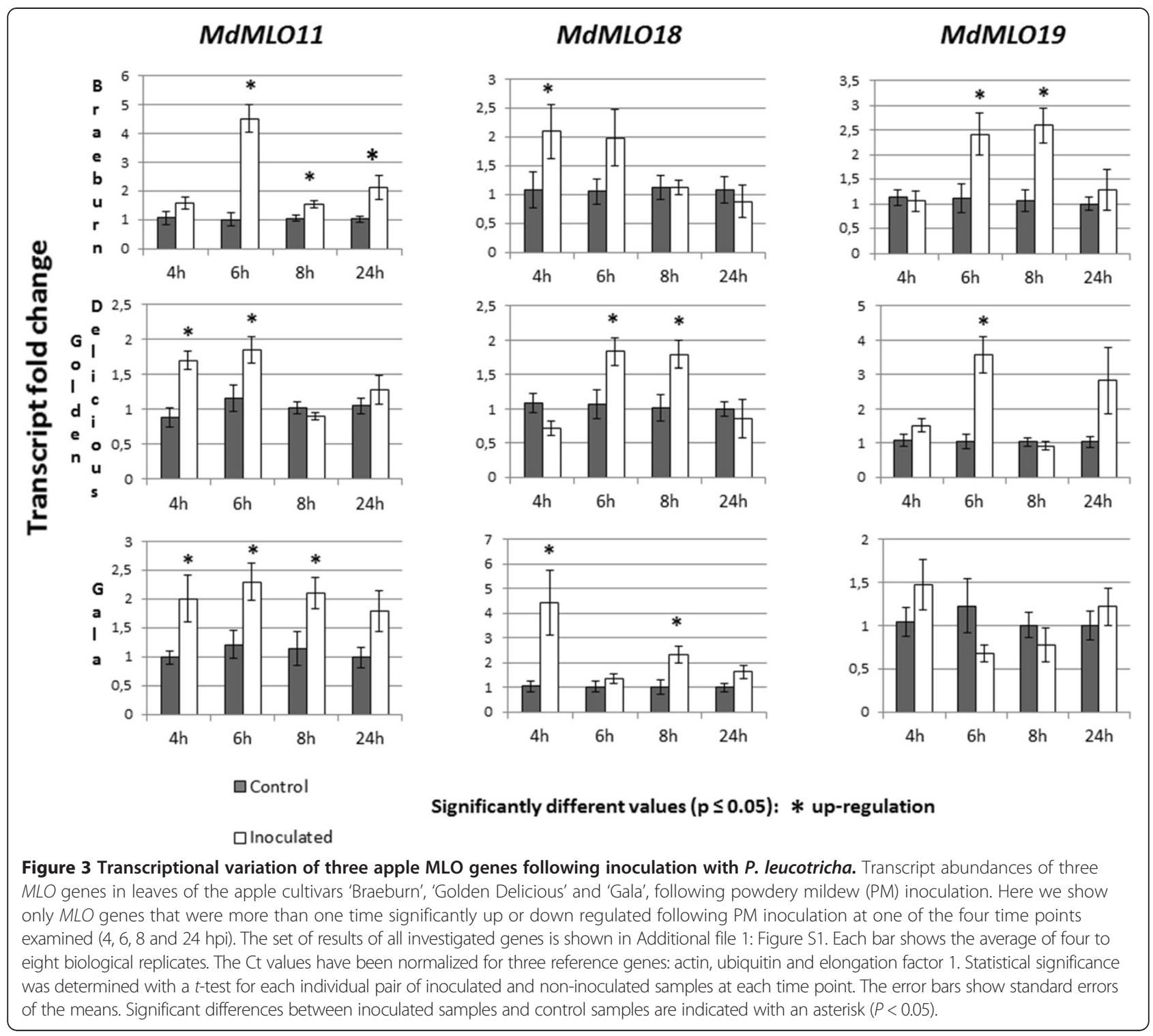

possible role of these genes as susceptibility factors has not yet been highlighted.

PpMLO3, PaMLO3 and FvMLO4 are likely to represent true orthologs of MdMLO19 (Table 4). Since orthologs often maintain the same function during evolution, we conjecture that the expression of these genes might also be responsive to PM fungi attacking corresponding species. Moreover, FvMLO15 and PpMLO9 are likely orthologs of $M d M L O 18$, so they should also be considered as putative transcriptionally responsive genes to PM fungi attack. Further studies aimed at the functional characterization of these genes (e.g. through the application of reverse genetic approaches of targeted mutagenesis or gene silencing), in apple but also in peach and strawberry, might lead to the identification of resistant phenotypes, which could be used for the development of PM resistant cultivars. Particularly, studies on MdMLO18 could lead to the characterization of a possible role for clade VII in the interaction with PM fungi.

\section{Conclusions}

Our work led to the identification of 19 MLO homologs in peach, 17 in strawberry and 21 in apple. Three, three and four homologs, respectively, belong to clade $\mathrm{V}$ and therefore are candidates for being S-genes. Due to the high similarity between peach and apricot, we were able to amplify and characterize three Clade V apricot $M L O$ genes.

The phylogenetic analysis revealed two new Rosaceae specific clades for the MLO family, although this needs to be confirmed by the use of a larger MLO proteins dataset.

Through inoculation of apple with $P$. leucotrica, we identified three up-regulated genes, i.e. MdMLO11, 
MdMLO18 and MdMLO19. MdMLO11 and MdMLO19, that belong to Clade V, are positioned in duplicated regions and have high sequence identity, therefore they are likely to be recent paralogs. MdMLO18 belongs to the newly identified Clade VII.

\section{Methods \\ In silico identification and comparison of MLO predicted proteins in peach, woodland strawberry and apple}

Predicted peptides from the peach genome (v. 1.0) and the strawberry genome (v.1.0) gene model databases, available at the website of the Genomic Database for Rosaceae (www.rosaceae.org) [35], were queried for the presence of MLO homologs protein sequences. First, a BLAST search, using the tomato SIMLO1 amino acid sequence as query was carried out. A further search was performed with the HMMER programme, which uses a method for homolog searches based on the profile hidden Markov probabilistic model [36]. The sequences obtained with the previously mentioned BLAST search, were used together with other known $M L O$ sequences from dicot and monocot species, namely: four RhMLOs from Rosa hybrida, 15 AtMLOs from Arabidopsis thaliana, SIMLO1 from Solanum lycopersicum, CaMLO2 from Capsicum annuum, PsMLO1 from Pisum sativum, MtMLO1 from Medicago truncatula, LjMLO1 from Lotus japonicus, VvMLO14 from $V$. Vinifera, HvMLO from Hordeum vulgare, TaMLO1_A1b and TaMLO_B1 from Triticum aestivum and OsMLO2 from Oryza sativa. MLO protein sequences from apple (Malus domestica cv. Golden Delicious) were identified by searching for the MLO domain profile (IPR004326) in the apple genome available at FEM-IASMA computational biology web resources (http://genomics.research.iasma.it). The resulting list was integrated with a BLAST search, carried out with the amino acid sequences previously listed for the HMMER search in peach and strawberry.

Chromosomal localization and predicted introns/exons structure of each $M L O$ gene of apple, peach and strawberry was deduced based on the available genomic information at the GDR database. The presence and number of membrane spanning helices was predicted using the online software InterPro (http://www.ebi.ac.uk/interpro). Alignments for conserved amino-acids analysis were performed with the CLC Sequence Viewer v. 6.9 software (http://clcbio.com).

A total of $90 \mathrm{MLO}$ protein sequences, including three apricot $M L O$ sequences isolated in vitro (see next paragraph), were used for Clustal alignment (http://www.ebi.ac. uk/Tools/msa/clustalw2/). UPGMA-based and NeighbourJoining-based phylogenetic trees were obtained with the CLC sequence viewer software. The UPGMA clustering algorithm was further used as input for the Dendroscope software, suitable for the visualization of large phylogenetic trees [37].
Relationships of orthology between $M L O$ candidate genes from peach, woodland strawberry and apple were inferred by running the GBrowse-Syn tool available at GDR (http://www.rosaceae.org/gb/gbrowse_syn/ peach_apple_strawberry) [35,38]. This displays syntenic regions among the three available genomes of Rosaceae, as detected by the Mercator programme [35,39]. For 50 $\mathrm{Kb}$ chromosomal stretches flanking each $P$. persica $P p M L O$ homolog, syntenic regions from $F$. vesca and $M$. domestica were searched. Orthology was called upon the identification of $F$. vesca or M. domestica MLO homologs within syntenic blocks.

\section{In vitro isolation of apricot MLO homologs}

RNA from apricot leaves (cultivar Orange Red) was extracted by using the SV Total RNA Isolation System Kit (Promega), and corresponding cDNA was synthesized by using the QuantiTect Reverse Transcription Kit (Qiagen) with oligo(dT) primers. Sequences of the peach $M L O$ homologs PpMLO1, PpMLO3 and PpMLO4, are phylogenetically close to $M L O$ homologs functionally associated to PM susceptibility, and were therefore used to design the primer pairs 5'-ATGGCAGCCGCAACCTCAGG AAGA-3'/5' -TTATATACTTTGCCTATTGTCAAAC-3', 5'-ATGGCAGGGGGAAAAGAAGGACG-3' $/ 5^{\prime}$-TCAAC TCCTTTCTGATTTCTCAA-3' and 5'-ATGGCCGA ACTAAGTAAAGA-3' $/ 5^{\prime}$ TCAACTTCTTGATTTTCC TTTGC-3', respectively. These were employed to amplify full-length cDNA sequences of apricot putative orthologs, by using the AccuPrime Taq polymerase (Invitrogen). Amplicons were purified by using the NucleoSpin Extract II kit (Macherey-Nagel) and ligated (molar ratio 1:1) into the pGEM-T Easy vector (Promega). Recombinant plasmids were cloned in E. coli DH10 $\beta$ chemically competent cells and recovered by using the Qiaprep spin miniprep kit (Qiagen). Sequencing reactions were performed twice, by using universal T7 and SP6 primers (Eurofins MWG Operon).

\section{Glasshouse test with apple cultivars}

A total of 192 apple plants from three cultivars (Braeburn, Golden Delicious and Gala) were used to measure transcript abundance of $M L O$ genes. Budwoods from these cultivars were grafted on M9 rootstocks in January 2012. The grafts were kept at $-1^{\circ} \mathrm{C}$ for 2 months, and potted at the beginning of March in greenhouse. The plants grew for 6 weeks in the greenhouse at $20^{\circ} \mathrm{C}$ during the day, $17^{\circ} \mathrm{C}$ during the night, relative humidity of $70 \%$ and natural day/ night cycle.

P. leucothrica was collected from apple trees in an unsprayed test orchard and used to infect greenhouse grown apple seedlings from 'Gala Galaxy' seeds. Four weeks after inoculation, conidia were used for the inoculation experiment, or transferred to new seedlings, to keep them viable. 
We inoculated by touching the plants with heavily infected apple seedlings. Control plants were not inoculated and kept separated in the same greenhouse of the inoculated plants. Inoculated and control plants were grown in the greenhouse at the growing conditions previously mentioned. The leaf samples were collected 4, 6, 8 and 24 hours post-inoculation (hpi).

Eight experimental repeats were performed and each sample contained three or four young leaves collected from each single plant. Every plant was used for sampling only once, to avoid any possible effect of wounding on the expression of $M L O$ genes. The smallest statistical unit was a plant. The leaves were flash-frozen and ground in liquid nitrogen, and stored at $-80^{\circ} \mathrm{C}$ until RNA extraction.

\section{qPCR analysis of transcript levels}

RNA extraction was carried out with the MagMAX-96 Total RNA isolation kit (Applied Biosystem) that includes DNAse treatment. The kit yielded between 50 and $200 \mathrm{ng} / \mathrm{ul}$, of good quality RNA per sample.

Primers for gene expression analysis were designed with NCBI Primer Designing Tool (http://www.ncbi.nlm.nih. gov/tools/primer-blast/). Four serial dilutions of cDNA (1/ $5-1 / 25-1 / 125-1 / 625)$ were used to calculate the efficiency of each primer pair with iCycler software (Biorad). In case of efficiency lower than 1.80 or greater than 2.20, the primer pair was discarded and a new one tested, with the exception of $M d M L O 9$, for which was not possible to design a primer pair with better efficiency. It was only possible to analyse $19 M L O$ genes because for $M d M L O 12$ and $M d M L O 16$ was not possible to design specific and efficient primer pairs, despite numerous attempts. Presence of a specific final dissociation curve was determined after each qPCR amplification reaction with progressive increment of temperature from $65^{\circ} \mathrm{C}$ to $95^{\circ} \mathrm{C}\left(0.5^{\circ} \mathrm{C}\right.$ each step, $\left.5 \mathrm{sec}\right)$ and the size of the product was confirmed by agarose gel electrophoresis.

Quantitative Real Time-PCR (qPCR) was performed with SYBR greenER mix (Invitrogen) in a $15-\mu \mathrm{L}$ reaction volume, using a Bio-Rad iCycler iQ detection system, run by the Bio-Rad iCycler iQ multicolor 3.1 software. The software applies comparative quantification with an adaptive baseline. Samples were run in two technical replicates with the following thermal cycling parameters: $95^{\circ} \mathrm{C} 3 \mathrm{~min}-95^{\circ} \mathrm{C} 15 \mathrm{sec}, 60^{\circ} \mathrm{C} 1 \mathrm{~min}$ (repeated 40 times) $-95^{\circ} \mathrm{C} 10 \mathrm{sec}$.

Reference genes $\beta$-actin (NCBI accession number DT002474; Plaza accession number MD00G171330 http://bioinformatics.psb.ugent.be/plaza/), ubiquitin (Plaza

Table 5 Gene-specific primers and amplicon sizes in qRT-PCR detection of 19 MdMLO-like genes based on Malus domestica cv. Golden Delicious genome sequence

\begin{tabular}{|c|c|c|c|c|}
\hline Gene & Forward primer $\left(5^{\prime}-3^{\prime}\right)$ & Reverse primer $\left(5^{\prime}-3^{\prime}\right)$ & Size (bp) & Efficiency \\
\hline MdMLO1 & GTGGGCTCGGTCGGCCAAAA & CCAGCACCAGCACCAGAACCA & 81 & 2.06 \\
\hline MdMLO2 & CGTTGGATCAACCACTGCGCCT & TGAGCTGCAGCCAGTGGGATCT & 87 & 1.83 \\
\hline MdMLO3 & CCACTGCGCCTCTCTGAAGCA & CCACCAAAACGGCTCTCCAGGT & 93 & 2.12 \\
\hline MdMLO4 & TGTTGCAGACACTATGCTGCCATGT & GGCAGCAGCTAAAGATCTGCGT & 109 & 1.87 \\
\hline MdMLO5 & TCGTCAGGCTCTCATTCGGGGT & GTGCTGCTGCCACTCCCTC & 132 & 1.80 \\
\hline MdMLO6 & TTCGCGGAGGAGGGGTCGTT & TTCGAGCGACAGCAACGGCA & 72 & 2.15 \\
\hline MdMLO7 & TGGAGCAAGTCACCAGTCTCCAT & CGCTTCCTGGTGCCAAATGTGC & 127 & 2.12 \\
\hline MdMLO8 & GTCAAGCTAATCTTACCACGCGCT & GGCTGGAAGGAAGGACAGCCA & 85 & 1.95 \\
\hline MdMLO9 & GCTGCAACACGTAATCACCC & AGAACGCCATTTCGAAAGCA & 173 & 2.30 \\
\hline MdMLO10 & GCGATCGTTGGCCTTGACTCC & TTCCGCGCTCGACAAGCAGA & 86 & 1.92 \\
\hline MdMLO11 & CCGTTCCATCACCAAGACGA & ATTGCTCTCCGAGTTACGCC & 102 & 1.90 \\
\hline MdMLO13 & ACATTGTCCCCAGGCTTGTT & GCCCAACCAATAAGTCCCGA & 151 & 2.00 \\
\hline MdMLO14 & TGCACTTGTCAGCCAGATGGG & GCATCTCCCACCCACGAACCG & 81 & 2.15 \\
\hline MdMLO15 & GCGCCTTTCTCTCTGCTGGGT & CGCGTGCGAGGTGGTCTCTT & 90 & 2.01 \\
\hline MdMLO17 & TTGCCACTGTATGCCTTGGT & TGCTTGCTTCTGTGCGAATG & 163 & 2.15 \\
\hline MdMLO18 & AAGGAAGGCTCTCATTCAGGCTCT & TGCAATTGGCTIITGACCAACGGT & 100 & 2.22 \\
\hline MdMLO19 & CAGAGTGGCGACTGCACTTA & GGGACATGGAGTGCAAAGGA & 110 & 1.97 \\
\hline MdMLO2O & AAAAAGCTCCACCAACCCCA & TTTCTCTCCCATGACGCTCG & 165 & 2.11 \\
\hline MdMLO21 & CCTTGTTCGAGGCCGTAGAG & ACCAAGTGCTTTGGTGGTTT & 176 & 1.95 \\
\hline$\beta$-actin & CTATGTTCCCTGGTATTGCAGACC & GCCACAACCTTGATTTTCATGC & 82 & 1.90 \\
\hline Ubiquitin & CATCCCCCCAGACCAGCAGA & ACCACGGAGACGAAGCACCAA & 349 & 1.91 \\
\hline Elongation Factor 1 & TACTGGAACATCACAGGCTGAC & TGGACCTCTCAATCATGTTGTC & 308 & 2.07 \\
\hline
\end{tabular}


accession number MD05G001920) and elongation factor 1 (Plaza accession number MD09G014760) were used as reference genes (Table 5). All these three genes were used in previous works [40-42]. For additional control, we assessed the stability of our genes with the software geNorm (medgen.ugent.be/ jvdesomp/genorm/). An M-value lower than 1.5 is generally considered as stable enough [43-45] and all three reference genes in all three cultivars considered are within this threshold. We saw differences in stability between cultivars: 'Golden Delicious' was the most stable cultivar (actin: 0.824 - ubiquitin: 0,852 elongation factor 1: 0,926), whereas 'Braeburn' was the less stable (actin: 1.246 - ubiquitin: 1,293 - elongation factor 1: 1,369$)$ and 'Gala' showed intermediate stability (actin: 1.039 - ubiquitin: 1,152 - elongation factor 1: 1,078).

Each of the biological replicates was analysed in duplicate and the average of these two replicates was used for further analysis. In case of excessive difference between the two replicates (one $\mathrm{Ct}$ or more), the run was repeated. Considering the high number of samples and genes of interest, we opted for this approach in order to reduce the number of total runs. Data analysis was performed according to Hellemans et al. [46], using the statistical package SPSS (IBM). This analysis method takes into account the efficiency value of each primer pair. For some genes it was necessary to apply a natural log transformation to the data, in order to obtain normal distribution of residues. To investigate the differences between control and inoculated samples, we used $T$-test $(\mathrm{p} \leq 0.05)$.

\section{Availability of supporting data}

The following files are available on: mynotebook.labarchives.com.

Figure 1 - Phylogenetic tree of Rosaceae MLO.

DOI: $10.6070 / \mathrm{H} 4 \mathrm{Z} 60 \mathrm{M} 0 \mathrm{~N}$.

Additional file 1 - Synteny between apple, peach and strawberry.

DOI: $10.6070 / \mathrm{H} 4 \mathrm{TD} 9 \mathrm{~V} 8 \mathrm{C}$.

\section{Additional files}

\section{Additional file 1: Synteny between apple, peach and strawberry}

Results of search for $F$. vesca and $M$. domestica regions syntenic to $50 \mathrm{~kb}$ P. persica chromosomal stretches containing the PpMLO homologs identified in this study. Shaded polygons indicate aligned regions between genomes. Grid lines are drawn to indicate insertions/deletions between the genomes of $F$. vesca and $M$. domestica with respect to the $P$. persica reference sequence. P. persica, F. vesca and $M$. domestica MLO homologs, named according to the nomenclature of the Genomic Database of Rosaceae, are boxed.

Additional file 2: Transcriptional variation of 19 apple MLO genes in three cultivars following inoculation with $P$. leucotricha.

Transcription abundances of 19 MLO-like genes following powdery mildew (PM) inoculation in 'Golden Delicious' (1a), 'Gala' (1b) and 'Braeburn (1c) leaf samples. The graphs show expression values of inoculated samples relative to control samples, averaged from four to eight biological replicate, normalized, that are in turn the average of two experimental replicates. The Ct values have been normalized with three reference genes: actin, ubiquitin and elongation factor 1 . Statistical significance was determined with a $t$-test for each individual pair of inoculated and control samples at each time point $(4,6,8$ and $24 \mathrm{hpi})$. The error bars show standard errors of the means. Significant differences between inoculated samples and control samples are indicated with a ${ }^{*}(P<0.05)$.

\section{Competing interests}

The authors declare that they have no competing interests.

\section{Authors' contribution}

SPe carried out the inoculation and gene expression analysis, identified MLO homologs in apple and wrote the major part of the manuscript. SPa contributed to design the experiment, identified MLO homologs in peach, apricot and strawberry, performed the analysis of synteny and contributed to write the manuscript. DC contributed to design the experiment, performed the phylogenetic analysis and revised the manuscript. AG contributed to design the experiment and revised the manuscript. YB contributed to the design of the experiments. RGFV contributed to the design of the experiments and revised the manuscript. MM contributed to the design of the experiments, contributed to the identification of MLO homologs in apple and revised the manuscript. HS contributed to the design of the experiments and revised the manuscript. All authors read and approved the final manuscript.

\section{Acknowledgment}

The authors would like to thank Remmelt Groenwold (WUR) for helping with apple inoculation with P. leucotricha and Lorenza Dalla Costa (FEM) for all the valuable advices about $\mathrm{QPCR}$ data analysis.

This work has been founded by Fondazione Edmund Mach and GMPF PhD programme.

\section{Author details}

${ }^{1}$ Department of Genomics and Biology of Fruit Crops, Fondazione Edmund Mach, via E. Mach 1, 38010 San Michele all'Adige, Italy. ${ }^{2}$ Wageningen UR Plant Breeding, Wageningen University and Research Centre, P.O Box 16, 6700 AA Wageningen, The Netherlands. ${ }^{3}$ Department of Soil, Plant and Food Science, University of Bari, Via Amendola 165/A, 70126 Bari, Italy. ${ }^{4}$ National Research Council, Institute of Plant Genetics, Via Amendola 165/A, 70126 Bari, Italy.

Received: 15 January 2014 Accepted: 10 July 2014

Published: 22 July 2014

\section{References}

1. Glawe DA: The powdery mildews: a review of the world most familiar (yet poorly known) plant pathogens. Annu Rev Phytopathol 2008, 46:27-51.

2. Turechek WW, Carroll JE, Rosenberger DA: Powdery Mildew of Apple. New York State Integrated Pest Management Program: Cornell Universit; 2004 (www.nysipm.cornell.edu/factsheets/treefruit/diseases/pm/apple_pm.pdf)

3. Foulongne $M$, Pascal T, Pfeiffer F, Kervella J: QTLs for powdery mildew resistance in peach $\times$ Prunus davidiana crosses: consistency across generations and environments. Mol Breed 2003, 12:33-50.

4. Boesewinkel HJ: Differences between the conidial states of Podosphaera tridactyla and Sphaerotheca pannosa. Annales de Phytopathologie 1979, 11:525-527.

5. Xiao CL, Chandler CK, Price JF, Duval JR, Mertely JC, Legard DE: Comparison of epidemics of botrytis fruit rot and powdery mildew of strawberry in large plastic tunnel and field production systems. Plant Dis 2001, 85:901-909.

6. Fu XL, LU Y, LiU XD, Li JQ: Crossability barriers in the interspecific hybridization between Oryza sativa and O. Meyeriana. J Integr Plant Biol 2009, 51:21-28.

7. Parlevliet JE: What is durable resistance, a general outline. In Durability of Disease Resistance. Edited by Jacobs TH, Parlevliet JE. Dordrecht: Kluwer; 1993:23-29.

8. Parisi L, Lespinasse $Y$, Guillaumes SJ, Kruger J: A new race of Venturia inequalis virulent to apples with resistance due to the Vf gene. Phytopathology 1993, 85:533-537. 
9. Krieghoff O: Entwicklung einer In-vitro-selektionsmethode auf Resistenz von Malus-Genotypen gegenüber Podosphaera leucotricha (Ell. Et Ev.) Salm. und In-vitron-Differenzierung von Virulenzunterschieden des Erregers. Berlin: PhD dissertation, Humboldt-Universität; 1995.

10. Pavan S, Jacobsen E, Visser RGF, Bai Y: Loss of susceptibility as a novel breeding strategy for durable and broad-spectrum resistance. Mol Breed 2010, 25:1-12.

11. Büschges $R$, Hollricher $K$, Panstruga $R$, Simons $G$, Wolter $M$, Frijters $A$, van Daelen R, van der Lee T, Diergaarde P, Groenendijk J, Töpsch S, Vos P, Salamini F, Schulze-Lefert $P$ : The barley Mlo gene: a novel control element of plant pathogen resistance. Cell 1997, 88(5):695-705.

12. Devoto A, Piffanelli P, Nilsson I, Wallin E, Panstruga R, Von Heijne G, Schulze-Lefert P: Topology, subcellular localization, and sequence diversity of the Mlo family in plants. J Biol Chem 1999, 274:34993-35004

13. Jørgensen $\mathrm{JH}$ : Discovery, characterization and exploitation of $\mathrm{Mlo}$ powdery mildew resistance in barley. Euphytica 1992, 63:141-152.

14. Consonni C, Humphry ME, Hartmann HA, Livaja M, Durner J, Westphal L, Vogel J, Lipka V, Kemmerling B, Schulze-Lefert P, Somerville SC, Panstruga R: Conserved requirement for a plant host cell protein in powdery mildew pathogenesis. Nat Genet 2006, 38(6):716-720.

15. Humphry M, Reinstädler A, Ivanov S, Bisseling T, Panstruga R: Durable broad-spectrum powdery mildew resistance in pea er1 plants is conferred by natural loss-of-function mutations in PsMLO1. Mol Plant Pathol 2011, 12(9):866-878.

16. Pavan S, Schiavulli A, Appiano M, Marcotrigiano AR, Cillo F, Visser RGF, Bai Y, Lotti C, Ricciardi L: Pea powdery mildew er1 resistance is associated to loss-of-function mutations at a MLO homologous locus. Theor App/ Genet 2011, 123:1425-1431.

17. Bai Y, Pavan S, Zheng Z, Zappel N, Reinstädler A, Lotti C, De Giovanni C, Ricciardi L, Lindhout P, Visser RGF, Theres K, Panstruga R: Naturally occurring broad-spectrum powdery mildew resistance in a Central American tomato accession is caused by loss of MLO function. Mol Plant Microbe Interact 2008, 21:30-39.

18. Aist JR, Bushnell WR: Invasion of plants by powdery mildew fungi, and cellular mechanisms of resistance. In The Fungal Spore and Disease Initiation in Plants and Animals. Edited by Cole GT, Hoch HC. New York: plenum press; 1991:321-345.

19. Miklis M, Consonni C, Bhat RA, Lipka V, Schulze-Lefert P, Panstruga R: Barley MLO modulates actin-dependent and actin-independent antifungal defense pathways at the cell periphery. Plant Physiol 2007, 144:1132-1143.

20. Panstruga R: Serpentine plant MLO proteins as entry portals for powdery mildew fungi. Biochem Soc Transact 2005, 33(Pt 2):389-392.

21. Piffanelli P, Zhou FS, Casais C, Orme J, Jarosch B, Schaffrath U, Collins NC, Panstruga R, Schulze-Lefert P: The barley MLO modulator of defense and cell death is responsive to biotic and abiotic stress stimuli. Plant Physiol 2002, 129:1076-1085.

22. Zheng Z, Nonomura T, Bóka K, Matsuda Y, Visser RGF, Toyoda H, Kiss L, Bai Y: Detection and quantification of Leveillula taurica growth in pepper leaves. Phytopathology 2013, 103:6.

23. Feechan A, Jermakow AM, Torregrosa L, Panstruga R, Dry IB: Identification of grapevine $M L O$ gene candidates involved in susceptibility to powdery mildew. Funct Plant Biol 2008, 35:1255-1266.

24. Winterhagen P, Howard SF, Qiu W, Kovács LG: Transcriptional up-regulation of grapevine MLO genesin response to powdery mildew infection. Am J Enol Vit 2008, 59:2

25. Kessler SA, Shimosato-Asano H, Keinath NF, Wuest SE, Ingram G, Panstruga R, Grossniklaus U: Conserved molecular components for pollen tube reception and fungal invasion. Science 2010, 330:968.

26. Chen Z, Noir S, Kwaaitaal M, Hartmann A, Wu MJ, Mudgil Y, Sukumar P, Muday G, Panstruga R, Jones AM: Two seven-transmembrane domain MILDEW RESISTANCE LOCUS O proteins cofunction in Arabidopsis root thigmomorphogenesis. Plant Cell 2009, 21:1972-1991.

27. Reinstädler A, Müller J, Czembor JH, Piffanelli P, Panstruga R: Novel induced mlo mutant alleles in combination with site-directed mutagenesis reveal functionally important domains in the heptahelical barley Mlo protein. BMC Plant Biol 2010, 10:31.

28. Devoto A, Hartmann HA, Piffanelli P, Elliott C, Simmons C, Taramino G, Goh CS, Cohen FE, Emerson BC, Schulze-Lefert P, Panstruga R: Molecular phylogeny and evolution of the plant-specific seven-transmembrane MLO family. J Mol Evol 2003, 56(1):77-88.
29. Elliott C, Muller J, Miklis M, Bhat RA, Schulze-Lefert P, Panstruga R: Conserved extracellular cysteine residues and cytoplasmic loop-loop interplay are required for functionality of the heptahelical MLO protein. Biochem / J 2005, 385(Pt 1):243-254.

30. Kaufmann H, Qiu X, Wehmeyer J, Debener T: Isolation, molecular characterization, and mapping of four rose MLO orthologs. Front Plant Sci 2012, 3:244

31. Elliott C, Zhou F, Spielmeyer W, Panstruga R, Schulze-Lefert P: Functional conservation of wheat and rice Mlo orthologs in defense modulation to the powdery mildew fungus. Mol Plant Microbe Interact 2002, 15(10):1069-1077

32. Velasco R, Zharkikh A, Affourtit J, Dhingra A, Cestaro A, Kalyanaraman A, Fontana P, Bhatnagar SK, Troggio M, Pruss D, Salvi S, Pindo M, Baldi P, Castelletti S, Cavaiuolo M, Coppola G, Costa F, Cova V, Dal Ri A, Goremykin V, Komjanc M, Longhi S, Magnago P, Malacarne G, Malnoy M, Micheletti D, Moretto M, Perazzolli M, Si-Ammour A, Vezzulli S, et al: The genome of the domesticated apple (Malus $\times$ domestica Borkh). Nat Genet 2010, 42:833-839.

33. Shulaev V, Sargent DJ, Crowhurst RN, Mockler TC, Folkerts O, Delcher AL, Jaiswal P, Mockaitis K, Liston A, Mane SP, Burns P, Davis TM, Slovin JP, Bassil N, Hellens RP, Evans C, Harkins T, Kodira C, Desany B, Crasta OR, Jensen RV, Allan AC, Michael TP, Setubal JC, Celton J, Rees DJG, Williams KP, Holt SH, Ruiz-Rojas JJ, Chatterjee M, et al: The genome of woodland strawberry (Fragaria vesca). Nat Genet 2011, 43:109-116.

34. Jung $\mathrm{S}$, Cestaro A, Troggio M, Main D, Zheng P, Cho I, Folta K, Sosinski B, Abbot B, Celton JM, Arùs P, Shulaev V, Verde I, Morgante M, Rokhsar D, Velasco R, Sargent DJ: Whole genome comparisons of Fragaria, Prunus and Malus reveal different modes of evolution between Rosaceous subfamilies. BMC Genomics 2012, 13:129.

35. Jung S, Ficklin SP, Lee T, Cheng C, Blenda A, Zheng P, Yu J, Bombarely A, Cho I, Ru S, Evans KM, Peace C, Abbott A, Mueller L, Olmstead M, Main D: The genome database for rosaceae (GDR): year 10 update. Nucleic Acid Res 2014, 42:D1237-D1244

36. Finn RD, Clements J, Eddy SR: HMMER web server: interactive sequence similarity searching. Nucleic Acids Res 2011, 39:W29-W37.

37. Huson D, Richter D, Rausch C, Dezulian T, Franz M, Rupp R: Dendroscope: an interactive viewer for large phylogenetic trees. BMC Bioinformatics 2007, 8:460.

38. McKay SJ, Vergara IA, Stajich JE: Using the generic synteny browser (GBrowse_syn). Curr Protoc Bioinformatics 2010, Chapter 9(Unit 9):12.

39. Dewey CN: Aligning multiple whole genomes with Mercator and MAVID. Methods Mol Biol 2007, 395:221-236.

40. Kürkcüoglu S, Degenhardt J, Lensing J, Al-Masri AN, Gaul AE: Identification of differentially expressed genes in Malus domestica after application of the non-pathogenic bacterium Pseudomonas fluorescensBk3 to the phyllosphere. J Exp Bot 2007, 58(3):733-741

41. Giorno F, Guerriero G, Baric S, Mariani C: Heat shock transcriptional factors in Malus domestica: identification, classification and expression analysis. BMC Genomics 2012, 13:639.

42. Dal Cin V, Danesin M, Boschetti A, Dorigoni A, Ramina A: Ethylene biosynthesis and perception in apple fruitlet abscission (Malus domestica L. Borck). J Exp Bot 2005, 56(421):2995-3005.

43. Ling D, Salvaterra PM: Robust RT-qPCR data normalization: validation and selection of internal reference genes during post-experimental data analysis. PLoS One 2011, 6:3.

44. Van Hiel MB, Van Wielendaele P, Temmerman L, Van Soest S, Vuerinckx K, Huybrechts R, Broeck JV, Simonet G: Identification and validation of housekeeping genes in brains of the desert locust Schistocerca gregaria under different developmental conditions. BMC Mol Biol 2009, 10:56.

45. Strube C, Buschbaum S, Wolken S, Schnieder T: Evaluation of reference genes for quantitative real-time PCR to investigate protein disulfide isomerase transcription pattern in the bovine lungworm Dictyocaulus viviparus. Gene 2008, 425:36-43.

46. Hellemans J, Mortier G, De Paepe A, Speleman F, Vandesompele J: qBase relative quantification framework and software for management and automated analysis of real-time quantitative PCR data. Genome Biol 2007, 8:R19.

doi:10.1186/1471-2164-15-618

Cite this article as: Pessina et al:: Characterization of the $M L O$ gene family in Rosaceae and gene expression analysis in Malus domestica. BMC Genomics 2014 15:618. 